\title{
The Intrarenal Venous Architecture of the Pig Kid- ney (Sus scrofa)
}

\section{Farag, F.M.M.}

\author{
Anatomy Department, Faculty of Veterinary Medicine, Cairo University, EGYPT
}

With 9 figures.

Received August, accepted for publication December 2012

\section{Abstract}

The aim of the present study was to explore the intrarenal ramifications of the renal vein in the kidney of the pig. For this purpose, the kidneys of eight adult pigs of both sexes were used. Corrosion casting and radiography revealed that the main stem renal vein was formed by the union of three renal veins, cranial, middle and caudal. The $3^{\text {nd }}$ order of branching was represented by 8-9 interlobar veins. The ventral half of the cranial end and the caudal third of the kidney were drained by the cranial and caudal renal veins as well as their large interlobar tributaries. The dorsal half was drained by small dorsal collateral veins that emptied into the ventral set. In the middle third of the organ, there were large veins in a close relationship to the ventral and dorsal surface of the uretero-pelvic junction in $75 \%$ and $25 \%$ of the specimens respectively. Numerous venous anastomoses were found throughout the renal parenchyma J. Vet. Anat. and on that basis we conclude that the renal venous system in the pig is not segmented. Our results are compared to those in other animal species and in humans.

Keywords: Pig Kidney, intrarenal, venous architecture.

\section{Introduction}

Many animals have been used as experimental models for urologic procedures. The pig kidney is often used due to the resemblance of its structural features to those of the human kidney (Sampaio et al., 1998 and Pereira-Sampaio et al., 2004). The pig kidney is also frequently used in the nephrolithotomy as a model for research (Kaouk et al., 2003) and training (Hammond et al., 2004 and Erap, 2003). Urologists have been looking for a better method to control bleeding during and after endourological procedures (Jua et al, 2004). Many studies have been done on the anatomy of the pig kidney, including its 
morphometric aspects (Sampaio et al,1998), the collecting system and arterial relationships (PereiraSampaio et al, 2004) as well as the intrarenal venous arrangement (Vodenicharov and gulubova, 1995 and Filho et al, 2008). However, this study is undertaken to extend knowledge of the intrarenal tributaries of the renal vein, as a way to help urologists in experimental research and urological surgical training when using the pig as an animal model.

\section{Material and Methods}

The kidneys of eight adult pigs of both sexes were used for this study. In addition, five pig feti were used to demonstrate the origin of the renal veins. Eight fresh unfixed kidneys (four rights and four left) were used for cast formation, these were manually dissected before corrosion to demonstrate the relationship between the intrarenal veins and the collecting system. The remaining eight kidneys were used for the radiographic study. The specimens were injected through the stem renal vein and in two specimens only the cranial and caudal renal veins were injected separately visualize the anastomoses between these veins.

Two approaches to injection were employed: one to visualize the veins in 3-dimensions in a plastic cast; and one for a radiological view using a radio-opaque filler material without corrosion.

1- Cast formation: This was composed of blue Kem-epoxy No. 151/ 20 , a mixture of solutions $A / B$ in a ratio of $3: 1$ respectively. The specimens were kept at room temperature for 4 days then corroded in $10 \% \mathrm{KOH}$ for $4-6$ weeks, then rinsed with a gentle stream of water.

2- Radio - opaque visualization: This was composed of a $30 \%$ suspension of red lead oxide colorless in Kem-epoxy No. 150. 2A:1B. It was examined at $55 \mathrm{k}$ v 30-70 $\mathrm{MA}, 0.5$ second and $\mathrm{FFd} 70 \mathrm{~cm}$.

The specimens were photographed using Olympus digital camera SP600UZ 12 mega pixel.

The results obtained were discussed and compared with those of other authors who performed earlier studies in the pig and other animals.

The nomenclature used here is that of the Nomina Anatomica Veterinaria (2005). Some additional terms were used based on that in the extant literatures which may not be recorded in the N.A.V. 


\section{Results}

\section{V. renalis}

The principal renal vein (Figs 1-9/1) was represented by a single vessel per each kidney entering the caudal vena cava on a level between the $2^{\text {nd }}$ and $3^{\text {rd }}$ lumbar vertebra. The right renal vein joined the vena cava slightly more cranial than the left one in three of the dissected pig embryos while in other two both veins joined the vena cava at the same level. The left renal vein crossed the ventral surface of the abdominal aorta and was relatively longer than the right one. The main stem renal vein was fed by three renal veins, cranial, middle and caudal. Each of these veins was responsible for the venous drainage of a corresponding portion of the kidney via a variable number of interlobar veins in the ventral half of the kidney, ventral to the collecting system while the dorsal half of the kidney was drained through smaller dorsal collateral veins that emptied into the dorsal aspects of these trunks.

\section{V. renalis cranialis}

The cranial renal vein (Figs 1-9/2) arose in the cranial portion of the kidney by the confluence of four cranial interlobar veins (I-IV), proceeded caudally for about $2-3 \mathrm{~cm}$ before it emerged from the cranial portion of the renal hilus. However in six of the examined specimens the cranial renal vein was formed only by three interlobar veins (I,II and III), while the fourth (IV) one emptied into the middle renal vein. Moreover, the cranial renal vein received three dorsal collateral veins $A$ and $B$ and $C$ that drained the corresponding dorsal portion. The veins $A$ (Figs $3,4 / 14$ ) drained the most cranial polar portion through 2-3 tributaries and emptied into the dorsal aspect of the interlobar vein I (12 specimens) or II (4 specimens). The vein B (Figs $3,4 / 15$ ) drained the caudal portion of the cranial $3^{\text {rd }}$ by 3-4 tributaries and terminated into the dorsal aspect of the cranial renal vein ( 10 specimens) or the interlobar vein IV (6 specimens). The vein C (Figs 3, 4/16) drained the dorsal aspect of the ureteropelvic region through two radicals and opened into the cranial renal vein near its origin.

\section{V. renalis medius}

The middle renal vein (Figs 1-9/3) was the smallest of the three main venous trunks of the stem renal vein. It measured about $2.0 \mathrm{~cm}$ in length and was formed by the union of two middle interlobar veins ( $V$ and $\mathrm{VI}$ ) which drained the middle third of the ventral half of the kidney (hilar zone). It also received one dorsal collateral vein D (Figs 3,4 / 
17) that drained the corresponding dorsal portion of the renal parenchyma through two main tributaries. The middle renal vein proceeded ventral to the collecting system in 12 specimens and dorsal to it in the other 4 specimens. In only two of the examined specimens the middle renal vein joined the stem renal vein while in 12 specimens it emptied into either the cranial renal vein (Figs 1-4 and 8) or into the caudal renal vein (Figs 5-7) in an equal percent. In the remaining two specimens the stem middle renal vein was absent (Fig 9) and the interlobar veins $\mathrm{V}$ and $\mathrm{VI}$ drained into the cranial and caudal renal veins respectively.

\section{V. renalis caudalis}

The caudal renal vein (Figs 1-9/4) from point of its size and direction represented the direct continuation of the stem renal vein. It was formed in the caudal portion of the kidney by the confluence of three caudal interlobar veins which could be designated as interlobar veins VII, VIII and IX that drained the caudal third of the ventral half of the kidney. It swerved cranially for about $2.5 \mathrm{~cm}$ caudal to the ureter then emerged from the caudal portion of the renal hilus and emptied into the stem renal vein. It is necessary to add that the caudal renal vein also received two dorsal collateral branches $(\mathbf{E})$ and $(\mathbf{F})$ that drained the corresponding dorsal half of the renal parenchyma. The vein $E$ (Fig. 3 and 4/18) was the largest of the dorsal collateral veins. It drained the cranial portion of the caudal $3^{\text {rd }}$ just caudal to the hilar zone of the kidney by 4-5 tributaries that radiated caudally towards the caudal pole of the kidney. The vein F (Fig. 3 and 4/19) drained the most caudal portion (caudal polar region) through 2-3 small radicles and emptied into the dorsal aspect of the interlobar vein IX (13 specimens) or VIII (3 specimens). However in four other specimens the later vein was absent and the tributaries of the vein $E$ extended to the caudal pole of the kidney.

\section{Vv. Interlobares}

The interlobar veins where represented by $8-9$ vessels that formed near the corticomedullary junction by the confluence of the arcuate veins and extended ventral to the main collecting ducts then between the calyces minor and medullary pyramids and joined forming the three main renal veins. These can be numbered in Roman numerals from I-IX and differentiated into three groups; cranial, middle and caudal. Those from I to IV ( Figs 2$5 / 5,6,7,8)$ represented the cranial group that formed the cranial renal vein and drain the corresponding 
third of the ventral half of the organ, while the interlobar veins $\mathrm{V}$ and $\mathrm{VI}$ ( Figs 2-5/ 9,10) represented the middle group forming the middle renal vein and draining the middle (hilar) zone. The remaining interlobar veins VII. VIII and IX (Figs 2-5 I 11, 12, 13) constituted the caudal group draining the corresponding $3^{\text {rd }}$ of the ventral half of the kidney and joined to form the caudal renal vein. Multiple longitudinal anastomoses were visible between the adjacent interlobar veins (Fig 5/l, I, III) throughout the renal medulla.

\section{Vv. Arcuata}

The arcuate veins (Figs 2, 3, 6, 7, 9/21) where connected to from the interlobar veins in the vicinity of the corticomedullary junction either in curved manner or at right angles or as a collateral tributaries. The arcuate veins anastomosed with each other forming a sort of 7-8 arches. These longitudinal arcades occur in different levels between the arcuate veins at the base of the medullary pyramids. The convex aspect of the later arches received the interlobular veins.

\section{Vv. Interlobulares}

The interlobular veins (Figs 2, 3, 6, 7, 9 /22) were represented by numerous vessels that follow a flexuous course in radial direction though the cortical tissue. They were formed by the confluence of numerous trees like tributaries that frequently received tufts of venous capillary network under the renal capsule.Multiple anastomoses were visible between the inter-lobular veins throughout the renal cortex and near the surface of the kidney. The aforementioned data revealed that numerous anastomoses were found in all renal parenchyma between the interlobar, the arcuate and dorsal collateral veins as well as the vertical anastomoses between dorsal collateral veins and the main ventral venous trunks as well as by circular anastomosis around the neck of the calyces minor forming collar-shaped venous anastomoses (Fig 1/20). On that basis the renal venous system in the pig could not be segmented.

\section{Discussion}

The present study revealed that each kidney was served by single principal renal vein connecting to the caudal vena cava. In the cat (Krahmer, 1966 and Webser, 1968), dog (Evans and Christensen, 1979) and lion (Abuzaid et al., 1993) both kidneys were drained by two renal veins. In the human kidney, any additional vessel that drains the kidney into the vena cava should be considered as a normal variation and may be named as an additional 
renal veins (Satyapal, 1993), or "accessory renal veins" ( Hazirolan et al., 2011). Bergman et al. (1988) reported that the multiple renal veins are rare on the left side and common on the right. Fernandes et al. (2005) recorded triple right renal veins in human. From the point of view of this work the presence of multiple renal veins could be explained as $2^{\text {nd }}$ order renal veins emptying directly into the vena cava without forming a stem renal vein.

The slight cranial displacement of the right renal vein compared to the left one that we observed in three dissected pig embryos is similar to that described by Nickel et al. (1976) and Ghoshal et al. (1981) in the pig. However in two other specimens both renal veins joined the vena cava at the same level, the same as has been recorded in the dog and cat (Koch, 1976) and pig (Vodenicharov and gulubova ,1995)

The current investigation revealed that, the stem renal vein in the pig arose from three tributaries: cranial, middle and caudal renal veins. In this respect, in the same species, Filho et al. (2008) recorded two main trunks cranial and caudal in $88.53 \%$ and three trunks, cranial, middle and caudal in $11.47 \%$ of the examined specimens. Similarly, Vodenicharov and Gulubova (1995) reported cranial and caudal renal veins in $75 \%$ and cranial, intermediate and caudal ones in $25 \%$ of the examined pig kidneys. On the contrary Oliveira (2008) mentioned that the renal vein was formed by two trunks in $25 \%$, three trunks in $55 \%$, four trunks in $15 \%$ and five ones in $5 \%$ of the examined bovine kidneys.

Satyapal (1993) recorded the systemic arrangement of the branching patterns of the human renal vein and concluded that there are five types; type (IA), comprised the two main tributaries, an upper and a lower primary one, type (IIA) added an intermediate one, type (IIIA) included the two main tributaries with an independent additional renal vein, type (IB) was formed of the two main tributaries with third posterior one and finally type (IIB) was formed of four tributaries; the upper, intermediate, lower and dorsal ones. On that basis the present study could be classed as types (IA) and (IIA).

The present study revealed that only the ventral half of the cranial and caudal thirds of the kidney were drained by the large veins represented by the cranial and caudal renal veins as well as their interlobar veins. The dorsal half was drained by small dorsal collateral veins that emptied by anastomoses into the ventral set. Similar findings 
were also recorded by Filho et al. (2008) in the pig. On the other hand Oliveira (2008) reported dorsal and ventral venous plexi in the cranial pole of the bovine kidney in $55 \%$ of cases. Similarly, in the human kidney (Sampaio and Aragao, 1990) the superior caliceal group involved dorsal and ventral large veins in $84.6 \%$ and the inferior caliceal group in $50 \%$, where large veins coursed parallel to the anterior and posterior surfaces of the caliceal infundibula. Due to these anatomical differences we realize that dorsal infundibualar puncture in the pig does not cause hazard to the veins and therefore, they don't cause back bleeding. On the contrary, in the middle third, there were large veins in a close relationship to the ventral and dorsal surface of the uretero-pelvic junction in $75 \%$ and $25 \%$ of the specimens respectively. Similarly Lee et al. (1988) and Clayman and Picus (1988) recorded $91.16 \%$ and 3.28 in the corresponding region of the human kidney and recommended that the deep incision of the uretero-pelvic junction to relieve its obstruction must be done laterally to avoid the risk of injury of large veins. Filho et al. (2008) observed large dorsal veins in the uretero-pelvic region in $55.78 \%$ of the cases and added that these veins were relatively smaller than those of the human kidney and consequently the direct dorsal puncture of the dorsal surface of the renal pelvis in the pig would not results in important vascular complications as in the human (Clayman et al.,1984).

In accordance with Filho et al. (2008) in the pig, the three primary tributaries of the stem renal vein were arising from the union of interlobar veins. On the other hand Vo-denicharov and gulubova (1995) in the same animal reported that the primary division of the renal vein was followed by secondary division into prelobar veins before giving 913 interlobar veins. The latter authors added that in $50 \%$ of the examined specimens the cranial renal vein was weaker and collected blood from the frontal third of the renal parenchyma while the caudal renal vein drained the remaining two thirds. However, the present study explained the later observations by the origin of the middle renal vein from the caudal renal vein in nearly half the examined specimens.

The current investigations revealed that there were free anastomoses between the intrarenal veins. The most frequent of these anastomoses were found in the longitudinal axis, in the medulla between the interlobar veins, at the 
base of the medullary pyramids between the longitudinal arcades formed between the arcuate vein and also in the cortex between the interlobular veins. Similar findings were recorded by (Sampaio and Aragao (1990) and Simpatico (1992) in human, Oliveira (2008) in bovine and Filho et al. (2008) in the pig kidney. It might be also added that the vertical venous anastomoses in the pig kidney were represented by the five directly emptying dorsal collateral veins into the interlobar veins as well as the numerous circular anastomoses which encircle the neck of the calyces minor resembling the collars of man (Sampaio and Aragao,1990). These data showed that the renal venous system in the domestic pig cannot be segmented.

According to the present study no superficial veins could be detected in the pig kidney. In this respect Zimmermann (1972) and Abuzaid et al. (1993) recorded superficial (capsular) veins in the kidney of the cat and lion respectively. Christensen (1952) in the dog, Zimmermann (1972), in the cat reported stellate veins that distributed all over the entire surface of the kidney and were always visible. Osman and Ragab (1987) in the donkey reported that the later veins were limited to the part caudal to the hilus and therefore could be considered as diagnostic feature of that kidney.

\section{References}

Abuzaid. S.M., Gad, M.R. and Wally, Y.R. (1993): Renal venous system of the lion (Panthera leo) a gross anatomical description. Vet. Med. J. Giza Vol. 41, No. 1, 131-135.

Bergman, R.A., Thompson, S.A., Afifi, A.K. and Saadeh, F.A. (1988): Compendium of human anatomy variation. Baltimore: Urbane \& Schwarzenberg.

Christensen, G.C. (1952): Circulation of the blood through the canine kidney. Am. J. Vet. Res., 13, 236-245.

Clayman, R.V. and Picus, D.D. (1988): Ureterorenoscopic endopyelotomy . Preliminary report. Urol. Clin. North Am. 15:433.

Clayman, R.V., Surya, V., Hunter, D., Castaneda-Zuniga, W.R., Miller, R.P. and Coleman, C. (1984): Renal vascular complications associated with the percutaneous removal of renal calculi. J. Urol.132:228. 
Erap P.P. (2003): Percutaneous renal surgery - new model for learning and training. Int. Braz. J. Urol. 29: 151.

Evans, H.E. and Christensen, G.C. (1979): Miller's Anatomy of the dog. Verlag. W.B. Saunders CO. Philadelphia, London.

Fernandes, R.M.P., Conte, F.H. P., Favorito, L.A, Figueiredo, M.A and Babinski M.A. (2005): Triple right renal vein: An uncommon variation. Int. J. Morphol. 23 (3): 231-233.

Filho, H.J., Pereira-Sampaio, M. A. , Favorito, L.A. and Sampaio, F.J. (2008). Pig kidney ]: anatomical relationships between the intrarenal Venous Arrangement and the kidney collecting system. J. Urol. Vol. 179, 1627-1630.

Ghoshal, N.G., Koch, T. and Popesko, P. (1981): The venous drainage of the domestic animals. W.B. Saunders Co. Philadelphia, London, Toronto, Sydney.

Hammond, L., Ketchum, j. and Schwartz, B.F. (2004): A new approach to urology training: A laboratory model for percutan- eous nephrolithotomy. J. Urol. 172:1950.

Hazirolan,T., Meryem, O. Turkbey, B., Karaosmanoglu, A.D., Oguz , B.S. and Canyigit, M. (2011). CT angiography of the renal arteries and veins: normal anatomy and variant. Diagn. Interv. Radiol. ,17, 67-73.

Jou,Y.C., Cheng, M.C., Sheen, J.H., Lin, C.T., and Chen, P.C. (2004): Electrocauterization of bleeding points for percutaneous nephrolithotomy. J. Urology 64 : 443.

Kaouk, J.H., Gill, I.S., Desai, M.M., Banks, K.L., Raja, S.S., Skacel, M. et al (2003): Laparoscopic anatrophic nephrolithotomy feasibility study in a chronic porcine model. J. Urol.; 169: 691.

Koch, T. (1976): Lehrbuch der veterinär Anatomie 13 and III, 3A, FLAGE, VEB Gustav Fischer Verlag, Jena.

Krahmer,R. (1966): Beitrag Zum Verhalten der Vena cava caudalis and ihres visceralen zulluss-gebietes bie der Katze. Anat. Anz. 118, 310-316. 
Lee, W.J., Badlani, G.H., Karlin, G.S. and Smith, A.D. (1988): Treatment of ureteropelvic structures with percutaneous pyelotomy. Experie-nce in 62 patients. AJR Am J. Roentgenol 151:515.

Nickel, R.A., Schummer, A. and Seifrle, E. (1976): Lehrbuch der Anatomie der Haustiere, Band III, Veralg Paul, Parey, Berlin

Oliveira, R.R. (2008): Bovine kidney: anatomical relationships between the intrarenal Venous Arrangement and the kidney collecting system. Braz. J. Morphol. Sci. 2008, Vol. 25 no. 1-4, p. 1-34.

Osman, F.A. and Ragab, S.A. (1987): Anatomical studies on the renal blood vessels of donkey (Equus asinus). Assiut Vet. Med. J. Vol. 18, No. 56.

Pereira-Sampaio,

M.A., Favorito, L.A. and Sampaio, F.J. (2004): Pig kidney: anatomical relationships between the intra-renal arteries and the kidney collecting system. Applied study for urological research and surgical training. J Urol. 172: 2077-2081.
Sampaio, F.J. (1992): Anatomical background for nephronsparing surgery in renal cell carcinoma. J. Urol.147:999.

Sampaio, F.J. and Aragao, A.H. (1990): Anatomical relationship between the renal venous arrangement and the kidney collecting system. J. Urol. 144: 1089.

Sampaio, F.J., Pereira-Sampaio, M.A. and Favorito, L.A. (1998): The pig kidney as an endo-urologic model: anato-mic contribution. J. Endourol. 1998, 12: 45.

Satyapal, K.S. (1993): An anatomical exploration into the variable patterns of the venous vasculature of the human kidney. Doctoral Thesis, University of Natal.

Vodenicharov, A. Gulubova, M. (1995): Renal venous architectonics in domestic swine. Anat. Histol. Embryol. 24:149.

Wesber, H. (1968): Ein Beitrag Zum problem der Verdoppelung der Vena cava caudalis bie der Katze.. Anat. Anz. 122: 491-495. 
Zimmermann, E. T. (1972): Das Blutgefassystem der Niere der
Katze (Felis catus L.). Diss. Vet. Med. Zurich.

\section{Legend for figs 1-9}

$1 \mathrm{~V}$. renalis, $2 \mathrm{~V}$. renalis cranialis, $3 \mathrm{~V}$. renalis medius, $4 \mathrm{~V}$. renalis caudalis, $5 \mathrm{~V}$. interlobaris I, $6 \mathrm{~V}$. interlobaris II, $7 \mathrm{~V}$. interlobaris III, $8 \mathrm{~V}$. interlobaris IV, $9 \mathrm{~V}$. interlobaris $\mathrm{V}, 10 \mathrm{~V}$. interlobaris $\mathrm{VI}, 11 \mathrm{~V}$. interlobaris $\mathrm{VII}, 12 \mathrm{~V}$. interlobaris $\mathrm{VIII}, 13 \mathrm{~V}$. interlobaris $\mathrm{IX}, 14 \mathrm{~V}$. collateralis dorsalis $\mathrm{A}, 15 \mathrm{~V}$. collateralis dorsalis $\mathrm{B}, 16 \mathrm{~V}$. collateralis dorsalis $\mathrm{C}$, $17 \mathrm{~V}$. collateralis dorsalis $\mathrm{D}, 18 \mathrm{~V}$. collateralis dorsalis E, $19 \mathrm{~V}$. collateralis dorsalis , 20 Collar shaped anastomoses, $21 \mathrm{Vv}$. Arcuata , $22 \mathrm{Vv}$. Interlobulares. A Extremitus cranialis, B Extremitus caudalis

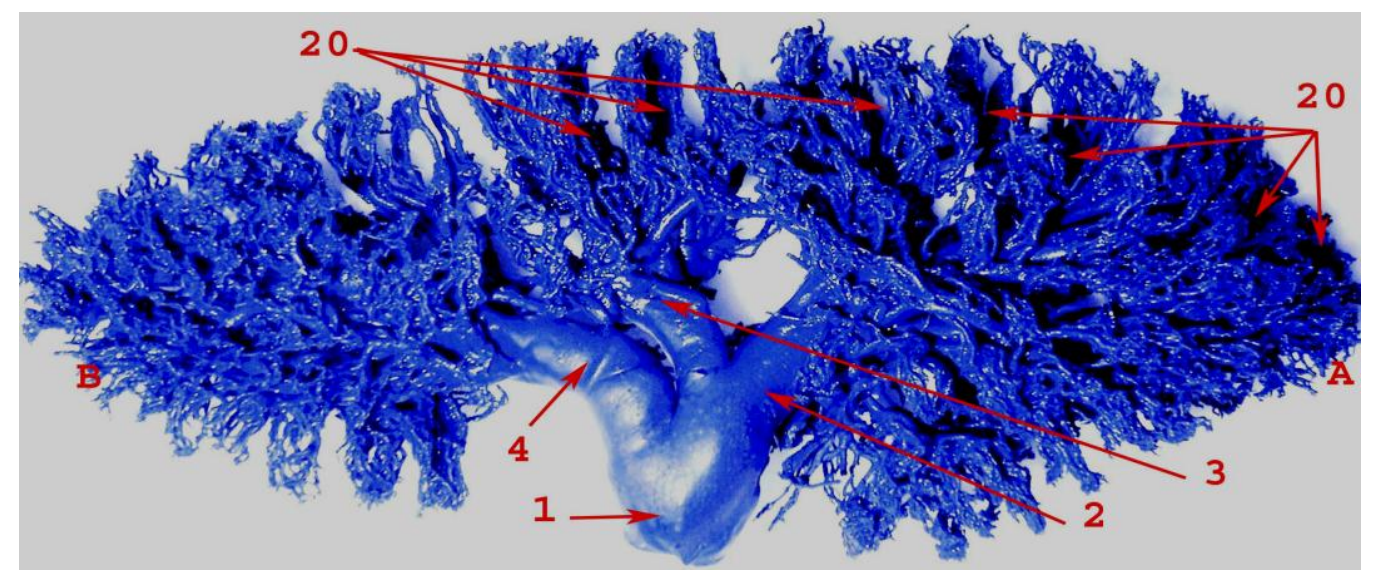

Fig (1): A photograph showing cast of the intra-renal veins in the right kidney of the pig (ventral view). 


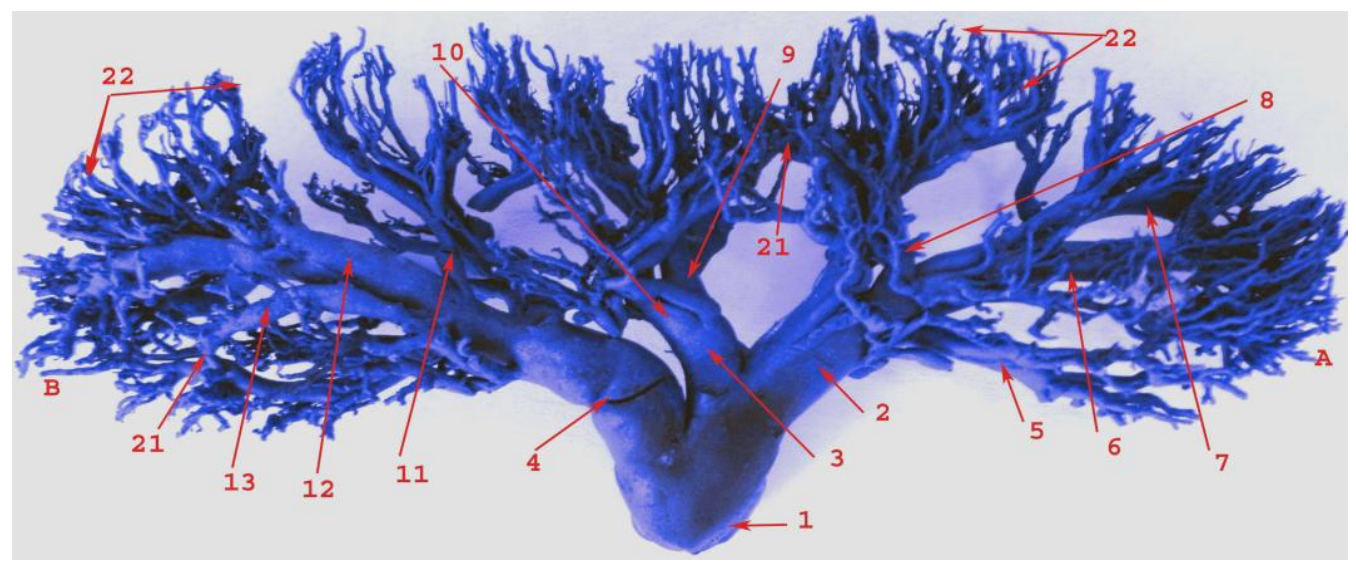

Fig (2): A photograph showing cast of the intra-renal veins in the right kidney of the pig (ventral view).

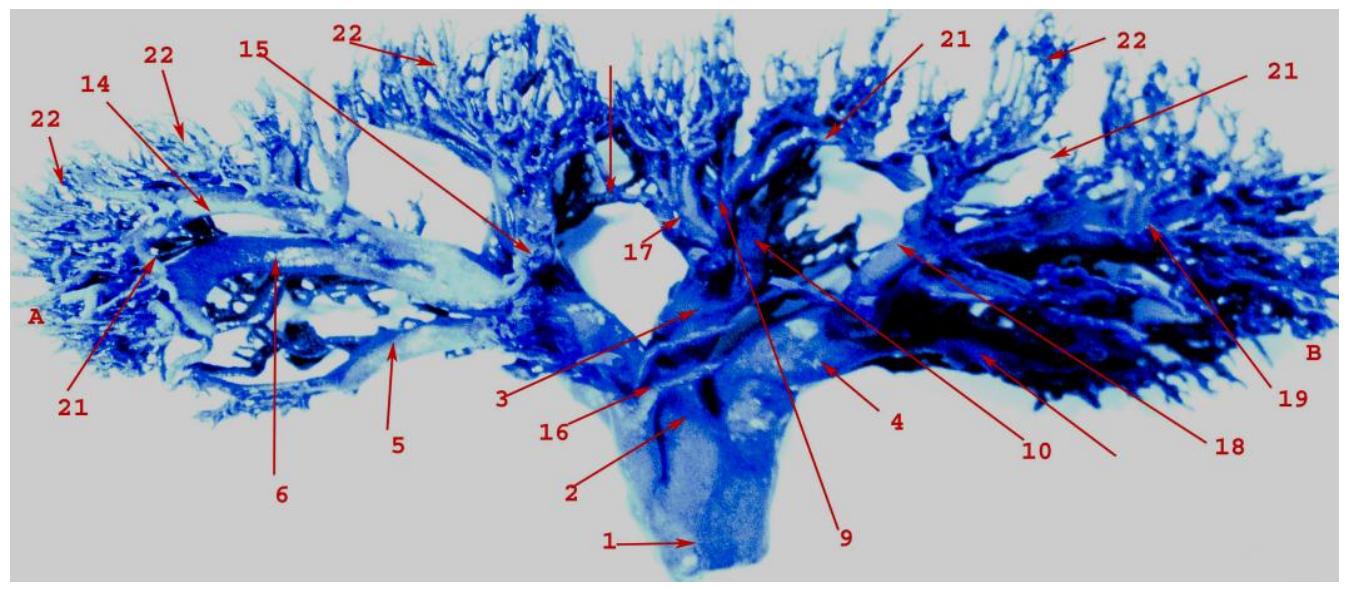

Fig (3): A photograph showing cast of the intra-renal veins in the right kidney of the pig (dorsal view). 


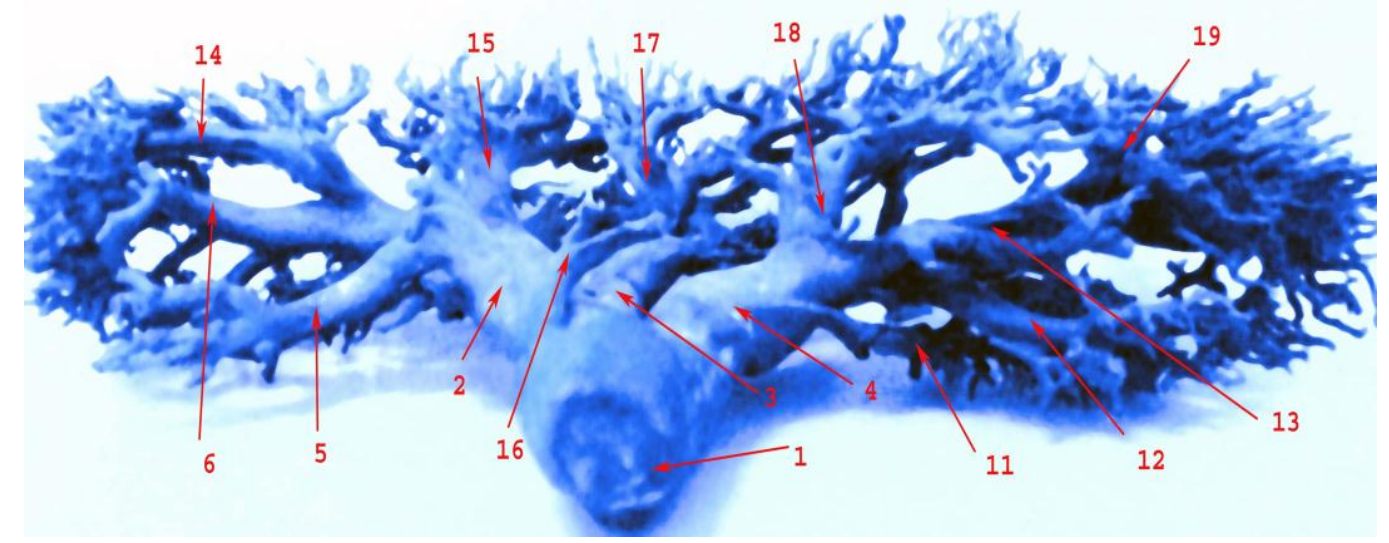

Fig (4): A photograph showing cast of the intra-renal veins in the right kidney of the pig (medial view). Note Arrangements of the veins into dorsal and ventral sets.

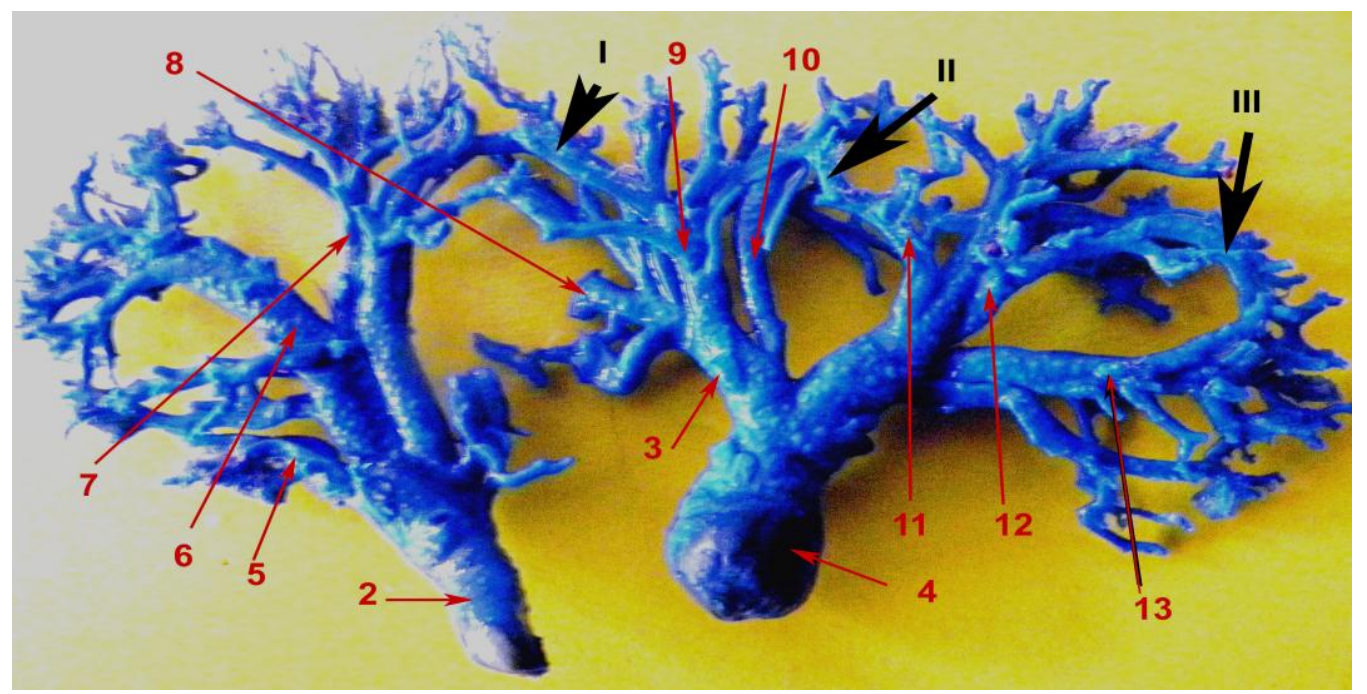

Fig (5): A photograph showing cast of the intra-renal veins in the left kidney of the pig (ventral view).

Each of the cranial and caudal renal veins was injected separately. Note: anastomoses between renal veins (black arrows I, II and III). 


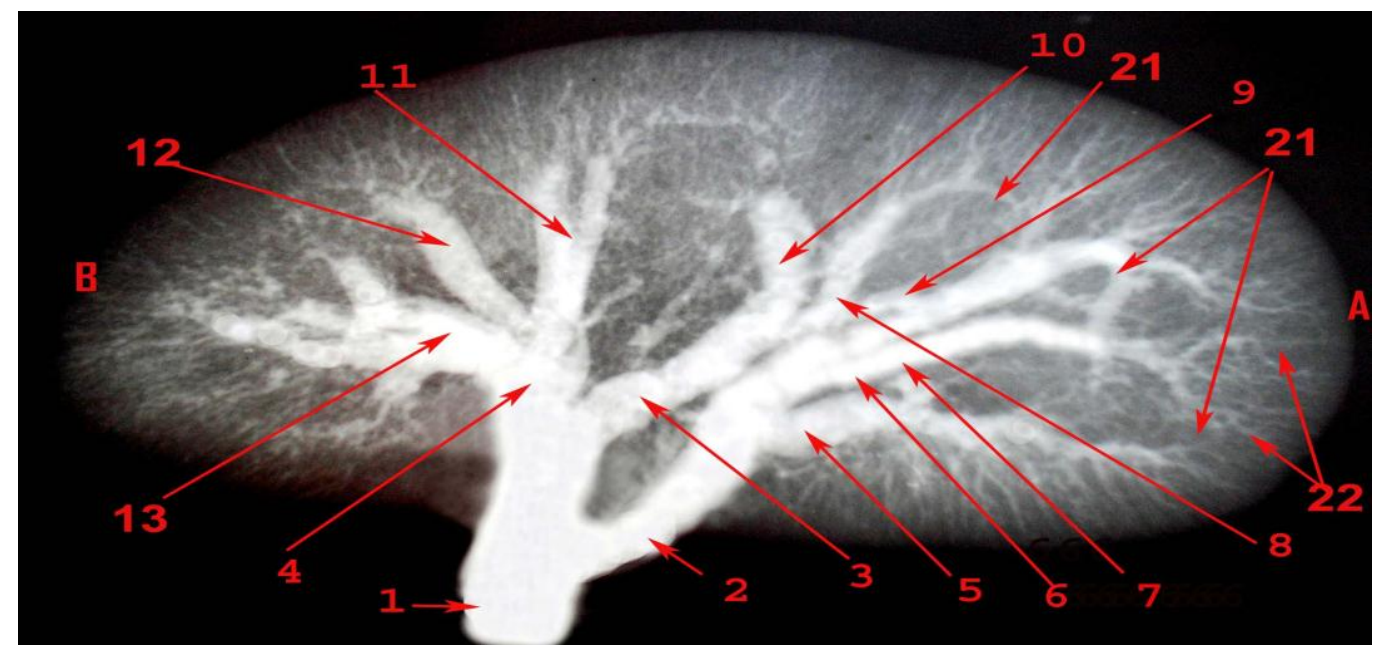

Fig (6): Radiograph showing ventral view of the intra-renal veins in the right kidney of the pig.

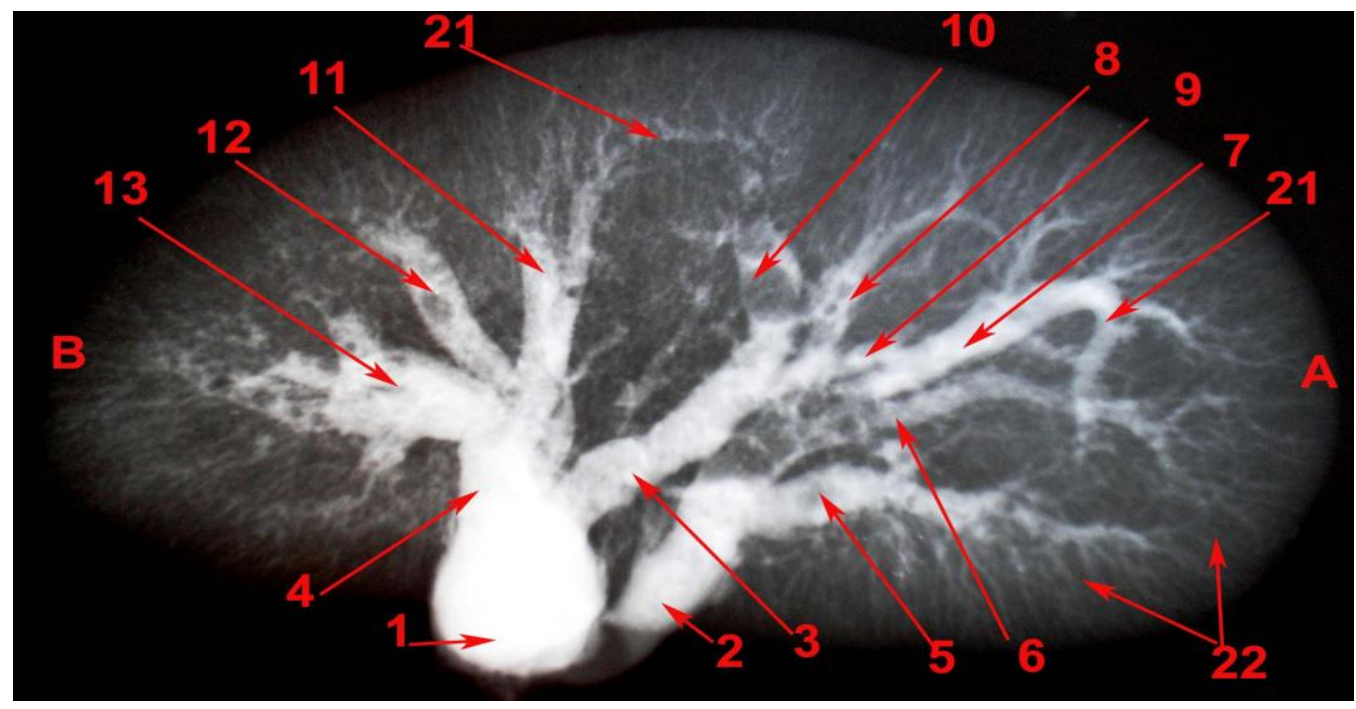

Fig (7): Radiograph showing ventral view of the intra-renal veins in the right kidney of the pig. 


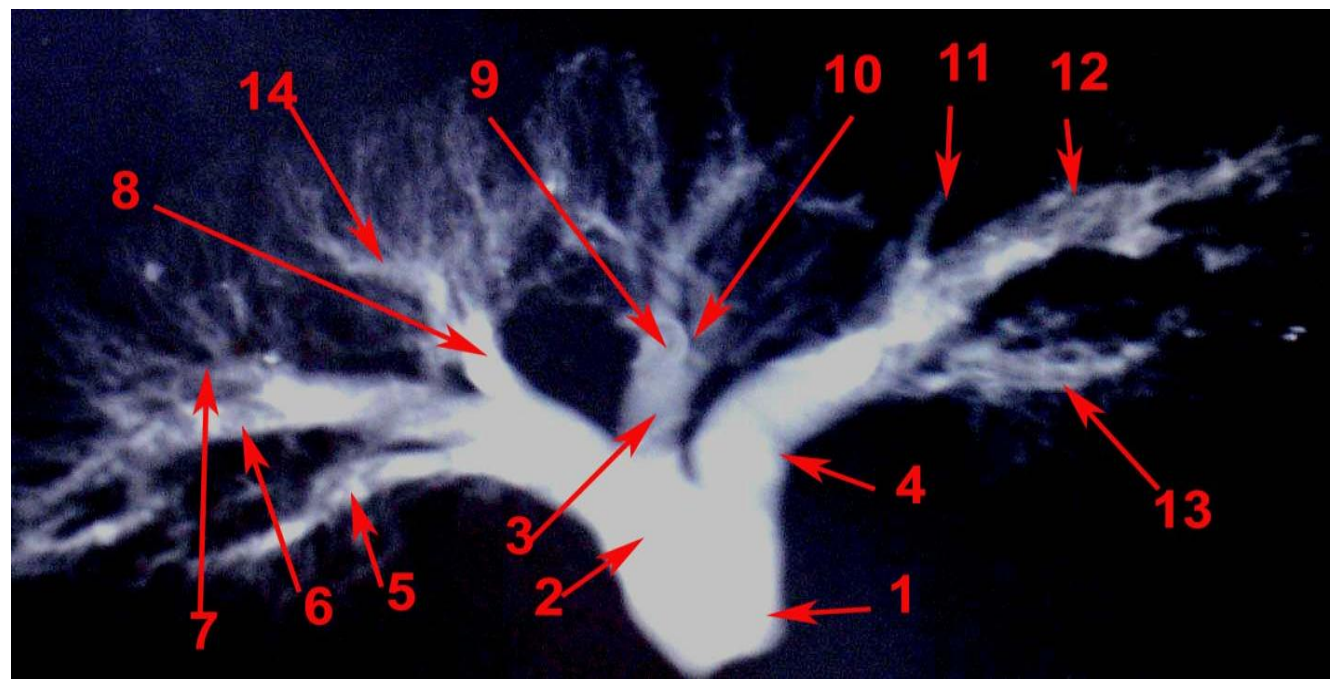

Fig (8): A radiograph showing ventral view of the intra-renal veins in the left kidney of the pig.

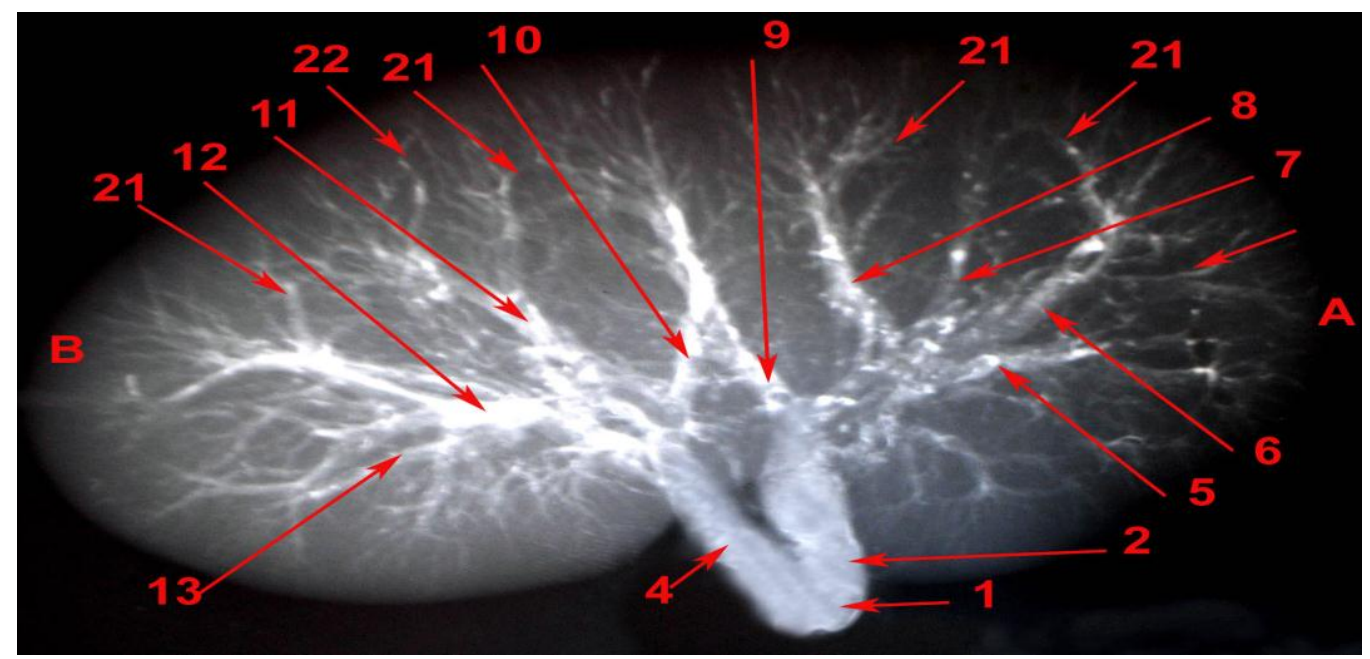

Fig (9): A radiograph showing ventral view of the intra-renal veins in the right kidney of the pig 